
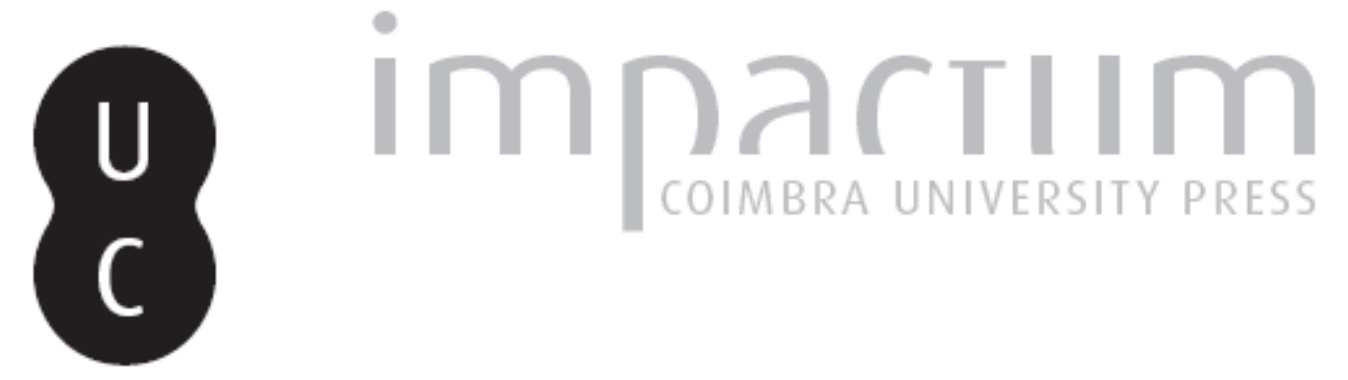

\title{
[Recensão a] TELO FERREIRA CANHÃO, Textos da Literatura Egípcia do Império Médio. Textos hieroglíficos, transliterações e traducões comentadas
}

Autor(es): $\quad$ Araújo, Luís Manuel de

Publicado por: Centro de História da Universidade de Lisboa

URL persistente:

URI:http://hdl.handle.net/10316.2/34999

DOI:

DOI:http://dx.doi.org/10.14195/0871-9527_23_12

Accessed : $\quad$ 26-Apr-2023 11:45:06

A navegação consulta e descarregamento dos títulos inseridos nas Bibliotecas Digitais UC Digitalis, UC Pombalina e UC Impactum, pressupõem a aceitação plena e sem reservas dos Termos e Condições de Uso destas Bibliotecas Digitais, disponíveis em https://digitalis.uc.pt/pt-pt/termos.

Conforme exposto nos referidos Termos e Condições de Uso, o descarregamento de títulos de acesso restrito requer uma licença válida de autorização devendo o utilizador aceder ao(s) documento(s) a partir de um endereço de IP da instituição detentora da supramencionada licença.

Ao utilizador é apenas permitido o descarregamento para uso pessoal, pelo que o emprego do(s) título(s) descarregado(s) para outro fim, designadamente comercial, carece de autorização do respetivo autor ou editor da obra.

Na medida em que todas as obras da UC Digitalis se encontram protegidas pelo Código do Direito de Autor e Direitos Conexos e demais legislação aplicável, toda a cópia, parcial ou total, deste documento, nos casos em que é legalmente admitida, deverá conter ou fazer-se acompanhar por este aviso.

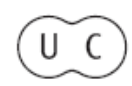



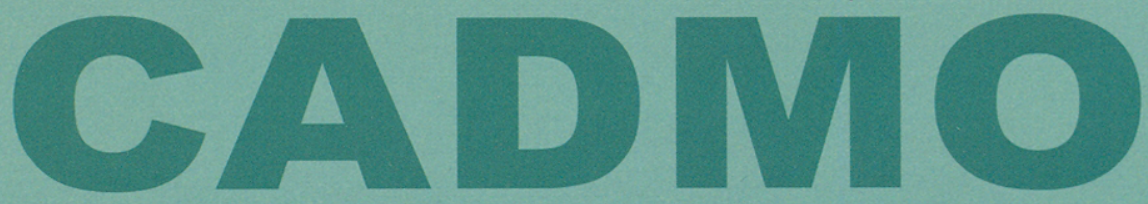

Revista de História Antiga

\author{
Centro de História \\ da Universidade de Lisboa
}

\title{
23
}

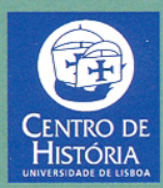

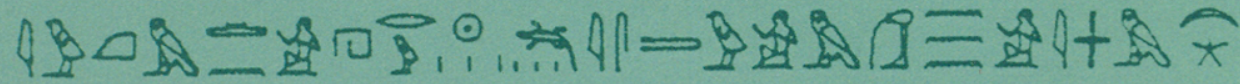

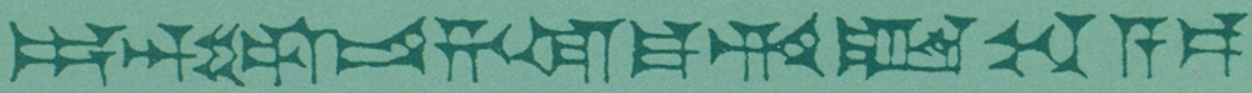
MHNIN AEI $\triangle \mathrm{E} \Theta \mathrm{EA}$ ПH$\Lambda \mathrm{HIA} \triangle \mathrm{E} \Omega$ 
TELO FERREIRA CANHÃO, Textos da Literatura Egípcia do Império Médio. Textos hieroglificos, transliterações e traducões comentadas, Lisboa: Fundação Calouste Gulbenkian, 2014, 1020 páginas. ISBN 978-972-31-1508-6

O egiptólogo Telo Ferreira Canhão está duplamente de parabéns - e a coincidência dá-se porque este livro, que reúne textos do antigo Egito, traduzidos e comentados a partir das versões originais, saiu na altura em que completava 60 anos de idade, e num momento em que a bibliografia egiptológica do nosso país se enriquecia com mais um elemento de trabalho muito útil para quem se dedica ao estudo e à docência da antiga civilização egípcia a nível académico e para as muitas pessoas que se interessam, por vezes com aliciante entusiasmo, pela história do país do Nilo.

Neste afã de enriquecimento da bibliografia portuguesa dedicada ao antigo Egito tem lugar preponderante a Fundação Calouste Gulbenkian, que já nos havia oferecido o catálogo sobre o belo acervo egípcio do seu Museu, intitulado Arte Egípcia (2006, com uma versão em inglês, Egyptian Art), e mais recentemente editou O Livro das Origens. A inscrição teológica da Pedra de Chabaka (2011), da autoria de Rogério Sousa, para agora aparecer, em momento propício, este encorpado e bem paginado volume, com mais de mil páginas, reunindo doze textos egípcios dessa fecunda e notável época histórica do país do Nilo que foi o Império Médio (c. 2040-1750 a. C.).

O Autor desta coletânea de textos traduzidos e comentados, que foram redigidos há quatro mil anos, é neste momento o mais habilitado egiptólogo no nosso país para fazer a tradução de textos originais em egípcio clássico, tarefa que já o havia ocupado nos últimos anos com a publicação de duas obras com prestigiadas chancelas nacionais: o Centro de História da Faculdade de Letras da Universidade de Lisboa editou O Conto do Náufrago, numa edição bilingue em português e em inglês (2012), e a Imprensa da Universidade de Coimbra foi a editora de Doze Textos Egípcios do Império Médio (2013). E note-se que ambas tiveram prefácios de reputados orientalistas e catedráticos jubilados da Faculdade de Letras da Universidade de Lisboa: o primeiro livro foi prefaciado pelo Professor José Augusto Ramos (atual diretor do Instituto 
Oriental) e o segundo pelo Professor José Nunes Carreira (fundador e primeiro diretor do Instituto Oriental).

Telo Canhão teve um percurso académico variegado e rico: estudou Arqueologia na Faculdade de Letras da Universidade de Coimbra, concluiu o seu mestrado em História das Civilizações Pré-clássicas na Faculdade de Ciências Sociais e Humanas da Universidade Nova de Lisboa, para depois rematar o seu convincente percurso académico com a exitosa apresentação da sua tese de doutoramento na Universidade de Lisboa, versando a temática onde com grande à-vontade se move: A Literatura Egípcia do Império Médio: espelho de uma civilização (2010).

Um candente aspeto com que o Autor se deparou no seu difícil trabalho de pesquisa e tradução foi a forma de apresentação dos textos, dado que reconhecer os textos egípcios como estando em prosa ou em verso nem sempre é fácil. E adrede explica: «Por vezes existem certas características gramaticais que nos ajudam, por exemplo, verbos ou frases narrativas, mas como a definição dos tipos literários depende muitas vezes da estrutura métrica, torna-se muito difícil em relação aos originais egípcios. Nalguns casos é mesmo impossível esse reconhecimento, uma vez que não utilizavam nem vogais nem acentuação, e usavam, de uma forma geral, proposições muito curtas.» Para esta ingente tarefa de lidar com a versificação foi útil seguir Gerhard Fecht e os seus trabalhos sobre a poesia egípcia, e para esmiuçar os casos de «paralelismo» que se detetam na arte de versejar cultivada pelos escritores egípcios, Telo Canhão colheu dados em Kenneth Kitchen, cuja funcional nomenclatura foi seguindo. Por aqui se vê como o autor alicerçou convenientemente o seu metódico e eficaz trabalho em reputados nomes da egiptologia (alguns já desaparecidos, mas cujo trabalho se mantém de útil consulta) que dedicaram uma especial atenção aos textos egípcios. E mais: para um maior apuro redacional das suas escorreitas versões em língua portuguesa, não dispensou a Nova Gramática do Português Contemporâneo, de Lindley Cintra.

Telo Canhão optou por dividir a apresentação dos textos traduzidos e comentados em quatro blocos: os contos (quatro), os discursos (quatro), as instruções (três) e os hinos (um). Antecedendo cada texto, dispõe o leitor de pequenos capítulos onde se enumeram as suas fontes com uma sinopse do respetivo texto, permitindo assim uma melhor apreensão da matéria correspondente a cada um dos quatro blocos, para os quais o Autor buscou uma certa harmonia entre aspetos temáticos e cronológicos, tendo embora em conta que há uma certa ambiguidade na datação de alguns desses textos.

Depois do prefácio (pp. 11-15), da autoria do recensor, vem a lista das abreviaturas e dos títulos que constam na obra (pp. 19-21), seguindo-se a 
Introdução (pp. 25-42) e as convenções seguidas na apresentação dos textos (pp. 45-48). Lendo as convenções fica o leitor preparado para uma melhor leitura das versões apresentadas, esclarecendo-se adrede a existência de linhas hieroglíficas a vermelho (respeitando a norma do original egípcio), bem como as respetivas linhas de transliteração e de tradução. Note-se que a transliteração segue aqui o modelo de Alan Gardiner proposto na sua Egyptian Grammar, dispensando assim certas «inovações» de transliteração que nos últimos anos têm aparecido mas que ainda não colheram aceitação generalizada. A tradução é em grande medida literal, dando por vezes frases em português que intrigarão o leitor - mas as abundantes notas esclarecem todas as eventuais perplexidades.

A coletânea abre com os contos, e com este género literário podemos fruir, com jubiloso agrado, a leitura de saborosos textos bem conhecidos e aqui reunidos sob o título de Khufu e os Magos (pp. 53-135, com notas nas pp. 136-165), denunciando pelo estilo uma clara proveniência cortesã que acaba por refletir a ambiência da IV dinastia, a dinastia das grandes pirâmides. São-nos oferecidos quatro contos de um conjunto maior, tendo restado apenas o inexpressivo final do conto que aludia ao Hórus Djoser (III dinastia), e que no seu tempo era conhecido por Netjerikhet. Está completo o conto com o provocatório título de «O marido enganado» (embora com algumas lacunas), e que termina com o castigo da mulher adúltera, que se tinha envolvido, com a serva, numa inédita ménage à trois com o concupiscente sedutor. $O$ conto seguinte é conhecido, entre outros títulos propostos, por "O passeio náutico", evocando a distração do rei Seneferu (IV dinastia) num barco movido por graciosas remadoras meio despidas, e que propicia um fenómeno de magia aquática a cargo do eficaz taumaturgo Djadjaemankh. Segue-se «O mago Djedi», capaz de recolocar cabeças cortadas de animais (mas não de seres humanos), que introduz o conto que relata "O nascimento dos príncipes» e que é afinal "O nascimento da V dinastia». Depois, com a História de Sinuhe (pp. 171-257, com notas nas pp. 258-285), vemos a superioridade do egípcio culto e que se vai saindo airosamente dos inopinados percalços da alteridade no seu exílio da Síria-Palestina, e relemos um dos mais paradigmáticos textos da literatura egípcia de todos os tempos onde é enfatizado o cumprimento das precípuas normas da maet, mesmo quando se está longe e no estrangeiro. O Conto do Náufrago (pp. 291-331, com notas nas pp. 332-345), patenteia nos seus versos o tom sapiencial que o Império Antigo já tinha anunciado e as insuperáveis vantagens de uma boa retórica, experimentada numa distante e luxuriante ilha. Depois vem o Conto do Camponês Eloquente (pp. 351-457, com notas nas pp. 458-507), e nele vemos os injustos doestos de um funcionário venal a serem superados pelos valores da justiça. 
Segue-se o género dos discursos, com quatro textos que são amiúde mencionados por quem habitualmente trata da literatura egípcia: As Admoestações de Ipu-uer (pp. 513-601, com notas nas pp. 602-627), com o autor egípcio a proclamar que a solução para os momentos de caos vivido em finais do Império Antigo (VI dinastia) e no incerto Primeiro Período Intermediário será a restauração da ordem no país. O Diálogo de um Desesperado com o seu Ba (pp. 633-672, com notas nas pp. 673-679), debate prementes questões como a vida e a morte e a existência no Além. Depois leremos As Profecias de Neferti (pp. 685-718, com notas nas pp. 719-741), como que a «legitimar» a tomada do poder faraónico pelo vizir Amenemhat (anunciado com o nome hipocorístico de Ameni, vindo do Sul, e que será o futuro rei Amenemhat I, fundador da XII dinastia) e a exaltar o comportamento do funcionalismo leal e eficaz. No final da resenha surgem As Lamentações de Khakheperréseneb (pp. 747-770, com notas nas pp. 771-775), tecendo-se em envolventes jogos de palavras que, tal como noutros textos daquela época, evidenciam o valor da retórica.

O género das instruções para "saber bem viver», uma expressiva designação para um tipo de textos que já remontava ao Império Antigo, está nesta coletânea bem documentado com a Instrução de Amenemhat ao seu filho Senuseret (pp. 781-806, com notas nas pp. 807-824), um texto de cariz sapiencial de grande envolvência político-ideológica que vem na senda de um texto anterior datado do Primeiro Período Intermediário e designado como Instrução para Merikaré, nome de um rei da $\mathrm{X}$ dinastia, com sede em Henen-nesut, que os Gregos chamarão Heracleópolis. Na Instrução Lealista (pp. 829-860, com notas nas pp. 861-869), relemos o texto gravado na Estela de Sehetepibré, que é incontornável como precípuo modelo que se insere num grupo de instruções lealistas para com o monarca beneficente, que na XII dinastia era apresentado como o «bom pastor». O género conclui com a Instrução de Kheti (pp. 875-922, com notas nas pp. 923-946), fazendo uma viva apologia do exercício da profissão de escriba contrapondo-a às outras atividades, tidas como desaconselháveis pela sua penosidade.

Quanto aos hinos, entre os vários que chegaram até nós datados do Império Médio, o Autor achou por bem escolher um exemplo deveras significativo, que é aliás paradigmático do género: Hinos ao rei Senuseret III (pp. 951-974, com notas nas pp. 975-979), onde se pode vislumbrar a imagem literária do faraó a complementar as representações escultóricas que dele conhecemos, e que antecede em muitos séculos a literatura hínica do Império Novo, com relevo para a hinografia amoniana e atoniana. Neste textos também se depreende que Telo Canhão prefere as versões onomásticas egípcias de Amenemhat e Senuseret (nomes muito divulgados durante o Império Médio), 
em lugar das inexpressivas formas gregas de Amenemmés e Sesóstris que poucos ainda usam.

Sopesando a organização interna da obra pode concluir-se que o critério assumido pelo Autor parece ser sensato e convidativo, com a divisão temática em quatro blocos: os contos, os discursos, as instruções e os hinos. Como o próprio reconhece, trata-se de uma organização subjetiva, mas que acaba por contemplar os textos mais ricos de conteúdo e que são suficientemente representativos da fase histórica em que foram produzidos, num momento civilizacional de grande florescimento atingido. Na verdade, a XII dinastia pode ser considerada como uma das mais notáveis entre as trinta dinastias que reinaram no país do Nilo. De resto, alguns dos seus mais consagrados monarcas são mencionados nos textos aqui reunidos: Amenemhat I, o fundador da dinastia, e seu filho Senuseret I, e sobretudo o enérgico Senuseret III, a quem foram dedicados hinos apologéticos como aquele que nesta obra consta, onde o famoso monarca é enaltecido como um campeão invencível na guerra contra os inimigos do Egito e como um paternal e generoso protetor das Duas Terras.

O volume remata com uma abundante lista da bibliografia consultada ( $\mathrm{pp}$. 983-1018), dividida em fontes, gramáticas, dicionários, glossários e léxicos hieroglíficos, além da listagem que inclui o programa informático hieroglífico e o suporte bibliográfico, e a bibliografia geral (marcando presença vários autores portugueses), seguindo-se o índice.

Dos textos que aqui são oferecidos já existiam traduções integrais, e em geral com comentários alusivos, em diversas línguas, nomeadamente em inglês, alemão e francês, cuja seriedade está bem assegurada por estarem ligadas a grandes nomes de egiptólogos que mais se empenharam no domínio da filologia. E nestas traduções para português que Telo Canhão produziu com grande competência, esses nomes vêm amiúde citados, como Richard Lepsius, Gaston Maspero, Adolf Erman, Charles Goodwin, Émile Suys, Aylward Blackman, Wladimir Golénischeff, Kurt Sethe, Winfried Barta, Hellmut Brunner, Alan Gardiner, Georges Posener, Gustave Lefebvre, F. Vogelsang, Pascal Vernus, Sérgio Donadoni, Hans Goedicke, Wolfgang Helck, Jan Assmann, Erik Hornung, William Kelly Simpson, Miriam Lichtheim, John Baines, Kenneth A. Kitchen, Raymond O. Faulkner, Vivian Davies, António Loprieno, James Allen, Richard B. Parkinson...

Esta panóplia de consagrados egiptólogos que se dedicaram, com mais ou menos profundidade, ao estudo da literatura do antigo Egito deixou de facto um trabalho vultuoso em várias línguas, possibilitando a muitos interessados na civilização egípcia o contacto com textos milenares que ainda hoje nos seduzem - mas a verdade é que em língua portuguesa ainda 
não tinha aparecido nada do género em tradução direta das fontes originais hieroglíficas. $\mathrm{E}$ eis que, finalmente, um egiptólogo português se debruçou sobre esse rico manancial que são as fontes literárias do Império Médio e as traduziu da língua de Sinuhe para a língua de Camões. Para benefício do leitor, essas traduções surgem dotadas de numerosas notas de rodapé que procuram ser bastante completas e explícitas, indo de simples referências filológicas a enquadramentos históricos, de comparações com outras traduções a opções pessoais acompanhadas pelas respetivas explicações, de comparações entre o egípcio hieroglífico e o egípcio hierático a variadíssimas justificações a diversos níveis, podendo ser um ponto de partida para muitas outras investigações e estudos.

O Autor destas esmeradas traduções de doze textos egípcios do Império Médio bem sublinhou, atempadamente, que não intentou oferecer aos seus leitores um produto final: «Procurou-se a perfeição, mas também sabemos o que é a utopia!» - confessa com justa e maética probidade Telo Canhão, para quem este trabalho pretende ser um ponto de partida e não um ponto de chegada, para destarte melhor servir a pequena comunidade científica portuguesa que se dedica aos estudos egiptológicos, ou, num âmbito muito mais alargado, provendo os investigadores e os docentes da área de História Antiga de fecunda motivação para estudos comparativos. Esta obra notável engrandece o seu autor no seio do pequeno mas ativo núcleo de egiptólogos portugueses, prestigia a coleção de «Textos Clássicos» das edições da Fundação Calouste Gulbenkian e honra sobremaneira o Centro de História da Universidade de Lisboa e a sua linha de investigação de «História Antiga e Memória Global».

\section{Luís Manuel de Araújo}

ALESSIA FASSONE e ENRICO FERRARIS, L'Égypte: L'Époque Pharaonique, Paris: Éditions Hazan, 2008, 384 pp., profusamente ilustrado. ISBN 978-2-7541-4

A série «Guide des Arts» oferece-nos esta bem paginada e bem ilustrada obra em francês, a partir do original italiano (integrado na coleção «Dizionari delle Civilitá» com direção de Ada Gabucci) que foi traduzido por Claire Mulkai.

$\mathrm{Na}$ Introdução (pp. 6-7) ficam claros os objetivos que presidiram à feitura desta obra, que, entre outros desideratos, pretende ser um elo de ligação entre a sensibilidade do homem moderno e as vivências do homem antigo que 